\title{
Effect of Chitosan Pre-Treatment on Color Fastness of Cotton Fabric with Natural Dyes from Mango Leaves Extract
}

\author{
Febri Fajri Yanti, Namira Rezqia Andevita, Ifa Puspasari* \\ Department of Chemical Engineering, Faculty of Industrial Technology, \\ Universitas Islam Indonesia \\ Jalan Kaliurang km 14,5 Sleman, Yogyakarta 55584, Indonesia \\ E-Mail : ifa.puspasari@uii.ac.id
}

\begin{abstract}
Application of natural dyes in textile coloring has been widely used because it is more environmentally friendly than synthetic dyes and is able to produce various colors from one natural dye. In this study, cotton fabric was treated with chitosan at different concentrations $(0$, $0.25 \%, 0.5 \%$, and $1 \%$ ) to determine its effect on the color fastness using mango leaves extract as natural dyes. Fastness to ironing, washing and sun drying of chitosan-treated samples were measured and compared with untreated samples. The effect of using different types of mordants (ferrous sulphate and alum) was also investigated. Coloring of the dyed fabric was evaluated in terms of color parameters ( $\mathrm{L}^{*} \mathrm{a}^{*} \mathrm{~b}^{*}$ ) and the dye absorption was evaluated using $\mathrm{K} / \mathrm{S}$ values. The results showed that the color fastness to wet and dry rubbing at each concentrations of chitosan and different types of mordants were good. However, the fabric processed with ferrous sulphate has a lower value of color fastness to ironing than that with alum. The color fastness to washing showed quite good results. The color fastness to sun drying showed that the cotton fabric with or without pre-treatment with chitosan showed good results. However, the value of fabric processed with ferrous sulphate showed very good values compared to alum. High values of K/S were obtained on fabrics pre-treated with chitosan for all types of mordants. Fabric processed with alum showed high color brightness.
\end{abstract}

Keywords: mango leaves; extraction; cotton fabric; chitosan; mordant; natural dye.

\section{Introduction}

Natural dyes for textiles have been widely studied from parts of trees, fruits, flowers, leaves, roots, and so on. The latest developments in natural textile dyeing nowadays are in terms of modification of natural and synthetic fibers using various preand post-treatment agents to improve color quality, fastness and functional characteristics of dyed fabrics. In addition, the research focus is also on the environmental compatibility aspect of the modification method.

Effect of various surface modifying agents containing anionic groups (Kim \& Park, 2007), and cationic groups (Bulut \& Akar, 2012), on the dyeing properties of fabrics with various types of natural dyes have been widely studied. The results showed that pre-treatment of various types of fabrics with cationic and anionic agents could significantly increase the color strength and fastness of dyed fabrics compared to untreated dyes.

Fiber surface modification using synthetic and natural polymers has also been used successfully to increase the absorption capacity of naturally dyed fibers (Janhom, et al., 2006). In recent years, several studies have been carried out to exploit the potential use of chitosan as a surface modification agent to improve the dye quality and biofunctionalization of cotton (Kavitha, et al., 2007), and wool fabrics (Giri Dev, Venugopal, Sudha, Deepika, \& Ramakrishna, 2009). Pre-treatment of fabrics with chitosan can increase the binding area for dyes resulting in better dye absorption (Chairat, Bremner, \& Chantrapromma, 2007). 
Several other studies have been carried out to exploit the potential application of chitosan as a surface modification agent to improve the color quality and biofunctionalization of the fibers. Davidson \& Xue (1994) found that the dyeing ability was better in wool treated with chitosan. Vakhitova \& Safonov (2003) found that using chitosan in an acid bath could increase the intensity and strength of the color. Houshyar \& Amirshahi (2002) investigated the treatment of cotton fabrics with chitosan and also found an increase in dye absorption.

Ali, El- Khatib, \& EL-Mohamedy (2019) showed that wool fibers pretreated with chitosan and dyed with saffron have higher color strength than untreated wool fibers. Pretreatment with chitosan also have shown to exhibit higher antimicrobial activity than untreated fibers. Yadav, Singh, Kaur, \& Sahu (2019) also confirmed that the combination of chitosan as mordant and turmeric and madder as natural dyes enhanced the antibacterial activity of wool fibers. Chilukoti, Venkatesh, \& Chandana (2019) studied cotton fabrics dyed with onion peel and used four different mordants. They concluded that premordanting with chitosan resulted in the highest K/S values. Ryu \& Bae (2018) studied the dyeing of Coptidis Rhizoma on cotton and wool fabrics. They found that using chitosan and tannin treatments on the fabrics, the K/S value increased by 3 times and 2 times for cotton and wool fabrics, respectively.

The main drawback in the application of chitosan pretreatment of wool and cotton fibers is the weak attachments between the fibers and chitosan. Lately, research has been conducted to improve the chemical bonding of chitosan onto the fiber substrate by treating with chitosan derivatives. Sadeghi-Kiakhani \& Safapour (2019) reported that pretreatment of wool yarns with chitosanpoly(amidoamine) dendrimer hybrid significantly improved the dyeing characteristics with madder as natural dye. Another study by Safapour, SadeghiKiakhani, \& Doustmohammadi (2019) treated wool yarn with chitosan-cyanuric chloride hybrid and dyed with cochineal. Their results showed that the chitosan hybrid treatment improved the dye uptake and decreased the dyeing time and temperature. The application of metal mordant was found unnecessary due to the bio-mordant role of the chitosan hybrid. The treated wool was also shown to exhibit antibacterial activity.

The textile dyeing using mango leaf extract has been studied by several researchers. Kartikasari \& Susiati (2016) conducted experiments on the dyeing of cotton fabric with mango leaf extract as natural dye using calcium carbonate $\left(\mathrm{CaCO}_{3}\right)$ and ferrous sulphate $\left(\mathrm{FeSO}_{4}\right)$ as mordants. Their results showed that dyeing using calcium carbonate resulted in pale yellow to light brown, whereas dyeing using ferrous sulphate showed greenish brown to dark greenish brown. Color fastness to sweat for both mordants showed good results. However, they did not test the color fastness to ironing, washing and sun drying. Several research has been done on natural dyeing for textile applications using mango leaves extract as natural dye. However, to the best of our knowledge, no research has been conducted on the use of chitosan to improve the dyeing of textile materials by using mango leaf extract as a natural dye.

This study examines the dyeing of cotton fabric treated with chitosan and using mango leaf extract as natural dye. The purpose of this study was to determine the staining and fastness properties of the dyed fabrics. Comparison between treated and untreated samples were examined, dye absorption was also evaluated in terms of $\mathrm{K} / \mathrm{S}$ values and CIELAB color difference values.

\section{Materials and Methods}

\subsection{Materials}

The main ingredient used as source of natural dye is mango leaves which are grown at the Faculty of Industrial Technology, Universitas Islam Indonesia, Yogyakarta. Cotton fabrics, ferrous sulphate, alum, dan TRO (Turkey Red Oil) were obtained from 
local store in Yogyakarta. Chitosan was purchased from PT Chemixs tbk.

\subsection{Experimental Method}

\subsubsection{Natural Dye Extraction}

Mango leaves were washed first and then dried. After that, the mango leaves were cut using scissors/knife into small pieces. One liter of water was added to fifty grams of mango leaves, and then heated in a beaker glass until the water reduced to half of the initial volume. The mixture was then filtered and the resulting filtrate is stored in another beaker glass.

\subsubsection{Preparation of Chitosan Solution}

Chitosan solution was prepared with varying concentrations of $0.25 \%, 0.50 \%$ and $1.0 \%$. Chitosan was dissolved in $1 \%$ acetic acid solution and left overnight at room temperature. Then the solution was filtered to remove insoluble materials.

\subsubsection{Preparation of Mordanting Solution}

Two types of mordants were used, namely alum $\left[\mathrm{K}_{2} \mathrm{SO}_{4} \cdot \mathrm{Al}_{2}\left(\mathrm{SO}_{4}\right)_{3} \cdot 24 \mathrm{H}_{2} \mathrm{O}\right]$ and ferrous sulphate $\left(\mathrm{Fe}_{2} \mathrm{SO}_{4}\right) .20$ grams of each type of mordants were dissolved in one liter of water, and then left overnight. Only the clear solution was taken for further process.

\subsubsection{Washing with TRO}

This process was done to increase the affinity of natural dye to the fabric and to reduce its surface tension. The cotton fabric was cut into $30 \mathrm{~cm} \times 30 \mathrm{~cm}$. Then it was soaked in 1 liter of water containing 2 grams of TRO for 30 minutes. After that the fabric was rinsed and dried.

\subsubsection{Pre-Treatment with Chitosan}

Fabric that have been washed with TRO were dipped in chitosan solution. The fabric was then heated in a water bath at $90{ }^{\circ} \mathrm{C}$ for an hour. After that, the fabric was dried in an oven for 5 minutes at $100{ }^{\circ} \mathrm{C}$.

\subsubsection{Dyeing with Natural Dye Extract}

After pre-treatment process with chitosan solution, the next step was dyeing process with mango leaves extract. Cotton fabric was dipped in the natural dyes for 15 minutes. After that, the fabric was aerated until it was almost dry. The fabric was then dipped again in the same dye. Dyeing was done repeatedly until the desired color was achieved. Then, the dyed fabric was dipped into the mordant solution.

\subsection{Analysis}

Color fastness to dry and wet rubbing was conducted using crockmeter (PT. Sekawan Solo, Indonesia). Color fastness to washing was tested using laundry-meter. Color strength of the dyed samples was measured using UV-PC Spectrophotometer in terms of $L^{*} a^{*} b^{*}$ and K/S values.

\section{Results and Discussion}

\subsection{Color Fastness to Rubbing}

Table 1 shows the results of color fastness of the dyed samples to dry and wet rubbing. From Table 1, the application of pre-treatment with chitosan at various concentrations did not show significant effect. In general, the color fastness to dry and wet rubbing at each concentration of chitosan and different types of mordants showed good results (3-5). However, mordanting using ferrous sulphate showed a lower value than that using alum.

This result is not consistent with the results from Ali, El- Khatib, \& ELMohamedy, 2019. They results showed that all treated fibers show better values than untreated fibers.

\subsection{Color Fastness to Washing}

Table 2 shows the results of color fastness of the dyed samples to washing. Based on the results shown in Table 2, the addition of chitosan at various concentrations during pretreatment of the fabric did not show a significant difference, although using different mordants. The value of color 
fastness to washing showed quite good results (3-4) for all samples.

\subsection{Color Fastness to Sun Drying}

The results of color fastness to sun drying are shown in Table 3. From Table 3, all samples, with or without pre-treatement with chitosan, showed a good value (3-5) of color fastness to sun drying. However, samples processed using ferrous sulphate showed excellent value compared to that using alum. This shows that the choice of mordant type affects the fastness of dyed fabrics.

Table 1. Color fastness to dry and wet rubbing

\begin{tabular}{|c|c|c|c|c|c|c|c|c|}
\hline \multirow{3}{*}{$\begin{array}{c}\text { Chitosan } \\
\text { concentration } \\
(\%)\end{array}$} & \multicolumn{8}{|c|}{ Mordant type } \\
\hline & \multicolumn{4}{|c|}{ Alum } & \multicolumn{4}{|c|}{ Ferrous sulphate } \\
\hline & \multicolumn{2}{|r|}{ Dry } & \multicolumn{2}{|r|}{ Wet } & \multicolumn{2}{|c|}{ Dry } & \multicolumn{2}{|c|}{ Wet } \\
\hline 0 & 5 & Excellent & $4-5$ & $\begin{array}{l}\text { Very } \\
\text { Good }\end{array}$ & $4-5$ & $\begin{array}{l}\text { Very } \\
\text { Good }\end{array}$ & $3-4$ & Good \\
\hline 0.25 & $4-5$ & $\begin{array}{l}\text { Very } \\
\text { Good }\end{array}$ & $4-5$ & $\begin{array}{l}\text { Very } \\
\text { Good }\end{array}$ & $4-5$ & $\begin{array}{l}\text { Very } \\
\text { Good }\end{array}$ & 3 & Good \\
\hline 0.5 & $4-5$ & $\begin{array}{l}\text { Very } \\
\text { Good }\end{array}$ & $4-5$ & $\begin{array}{l}\text { Very } \\
\text { Good }\end{array}$ & $4-5$ & $\begin{array}{l}\text { Very } \\
\text { Good }\end{array}$ & 3 & Good \\
\hline 1 & $4-5$ & $\begin{array}{l}\text { Very } \\
\text { Good }\end{array}$ & 5 & Excellent & $4-5$ & $\begin{array}{l}\text { Very } \\
\text { Good }\end{array}$ & 3 & Good \\
\hline
\end{tabular}

Table 2. Color fastness to washing

\begin{tabular}{|c|c|c|c|c|}
\hline \multirow{2}{*}{$\begin{array}{c}\text { Chitosan } \\
\text { concentration } \\
(\%)\end{array}$} & \multicolumn{4}{|c|}{ Mordant type } \\
\hline & \multicolumn{2}{|c|}{ Alum } & \multicolumn{2}{|c|}{ Ferrous sulphate } \\
\hline 0 & 3 & Good & 4 & Very Good \\
\hline 0.25 & 4 & Very Good & 3 & Good \\
\hline 0.5 & 4 & Very Good & 3 & Good \\
\hline 1 & 3 & Good & $3-4$ & Good \\
\hline
\end{tabular}

Table 3. Color fastness to sun drying

\begin{tabular}{|c|c|c|c|c|}
\hline \multirow{3}{*}{$\begin{array}{c}\begin{array}{c}\text { Chitosan } \\
\text { concentration }(\%)\end{array} \\
0\end{array}$} & \multicolumn{4}{|c|}{ Mordant type } \\
\hline & \multicolumn{2}{|r|}{ Alum } & \multicolumn{2}{|c|}{ Ferrous sulphate } \\
\hline & 3 & Good & 5 & Excellent \\
\hline 0.25 & $3-4$ & Good & 5 & Excellent \\
\hline 0.5 & $3-4$ & Good & 5 & Excellent \\
\hline 1 & $4-5$ & Very Good & 5 & Excellent \\
\hline
\end{tabular}




\subsection{K/S Value}

Figure 1 shows the K/S of all samples tested. From Figure 1, it was found that higher K/S values were found in fabrics pretreated with chitosan for all types of mordants compared to that without pretreatment with chitosan. This is because chitosan has high affinity for dye. Type of mordant used also affects the K/S values. In this study, the results show that the cotton fabrics processed with ferrous sulphate exhibit significantly higher K/S values (Figure 1a) compared to the fabrics processed with alum (Figure 1b).

This finding is also consistent with the other findings. Ali, El- Khatib, \& ELMohamedy (2019) showed that the color strength of pretreated wool fibers with nanochitosan and chitosan and dyed with saffron red and yellow mixture has high value of color strength than untreated wool fibers. The same observation was also found by Yadav, Singh, Kaur, \& Sahu (2019). They also found that increasing chitosan concentration will increase the K/S value.

\subsection{Color Parameters}

Table 4 shows the results of the color difference test for fabrics dyed using alum and ferrous sulphate. From Table 4, it is clear that treating with chitosan generally could decrease the values of $\mathrm{L}^{*}$ meaning that the color of the treated fabrics got darker than the untreated fabrics. The same observation was also obtained by Ali, El- Khatib, \& ELMohamedy (2019).

Table 4 also shows that type of mordants influences the resulting color brightness; high color brightness was shown in fabric dyed using alum. The $b^{*}$ value for alum also shows a high positive value which indicates that the fabric dyed using alum is in a more yellowish in color compared to that of ferrous sulphate.

Figure 2 shows the photograph of the cotton fabrics dyed with ferrous sulphate (a) and alum (b).
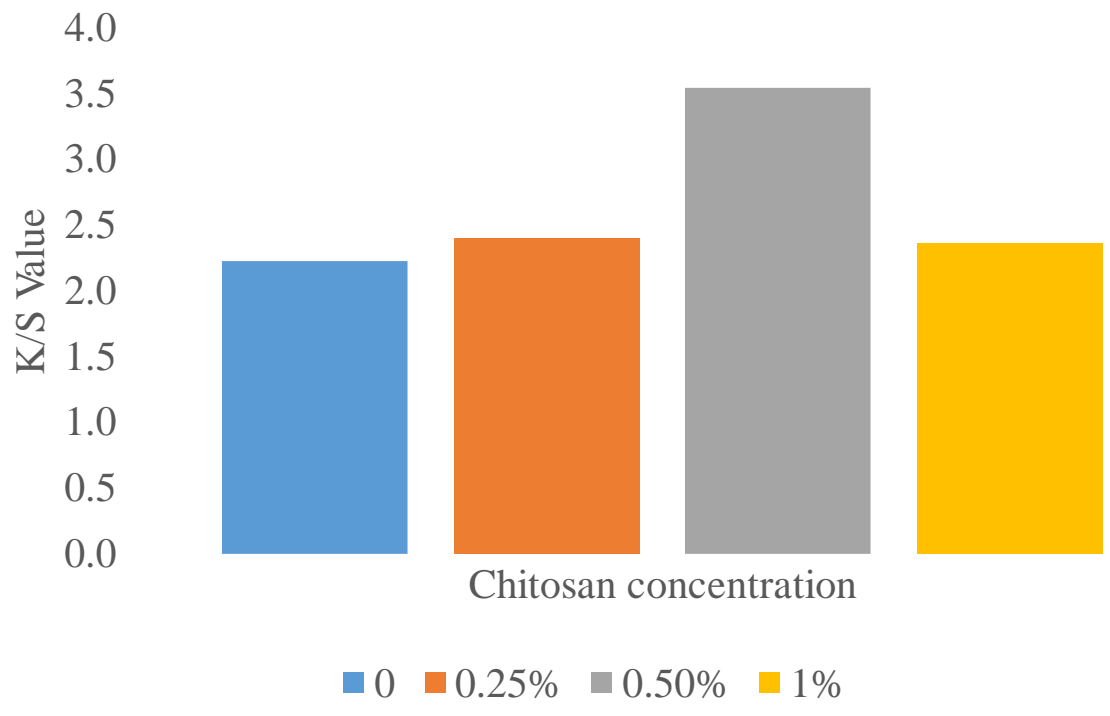

(a) 

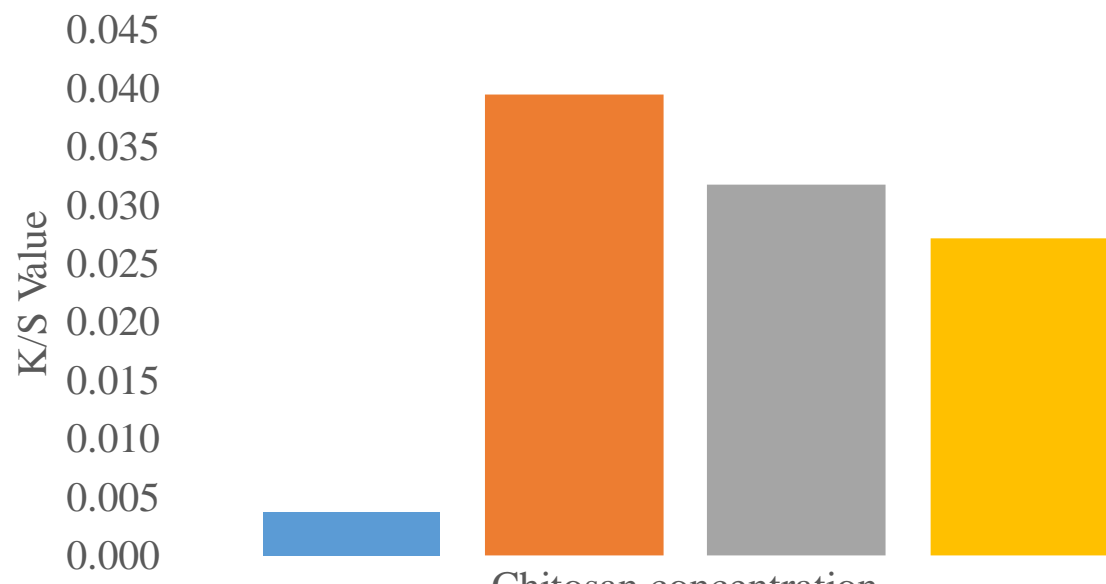

Chitosan concentration

$=0.25 \% \quad 0.50 \% \quad \square 1 \%$

Figure 1. K/S values for dyed cotton fabric with mordant type: (a) ferrous sulphate $\left(\mathrm{Fe}_{2} \mathrm{SO}_{4}\right)$; (b) alum

Table 4a. Color parameters $\left(\mathrm{L}^{*} \mathrm{a}^{*} \mathrm{~b}^{*}\right)$ for dyed cotton fabric with ferrous sulphate

\begin{tabular}{cllll}
\hline $\begin{array}{c}\text { Chitosan concentration } \\
(\%)\end{array}$ & $\mathbf{L}^{*}$ & $\mathbf{a}^{*}$ & $\mathbf{b}^{*}$ & $\mathbf{d E}^{* \mathbf{a b}}$ \\
\hline $0 \%$ & 43,66 & $-0,81$ & 8,82 & 57,53 \\
$0.25 \%$ & 39,95 & $-0,96$ & 7,10 & 60,98 \\
$0.5 \%$ & 26,28 & $-1,19$ & 6,86 & 74,56 \\
$1 \%$ & 43,51 & $-0,81$ & 8,87 & 57,68 \\
\hline
\end{tabular}

Table 4b. Color parameters ( $\left.\mathrm{L}^{*} \mathrm{a}^{*} \mathrm{~b}^{*}\right)$ for dyed cotton fabric with alum

\begin{tabular}{cllll}
\hline $\begin{array}{c}\text { Chitosan concentration } \\
(\%)\end{array}$ & $\mathbf{L}^{*}$ & $\mathbf{a}^{*}$ & $\mathbf{b}^{*}$ & $\mathbf{d E}^{*} \mathbf{a b}$ \\
\hline $0 \%$ & 91,42 & $-6,33$ & 25,98 & 27,99 \\
$0.25 \%$ & 82,00 & $-6,01$ & 34,86 & 39,69 \\
$0.5 \%$ & 83,13 & $-6,01$ & 36,38 & 40,56 \\
$1 \%$ & 85,69 & $-4,74$ & 34,13 & 37,26 \\
\hline
\end{tabular}




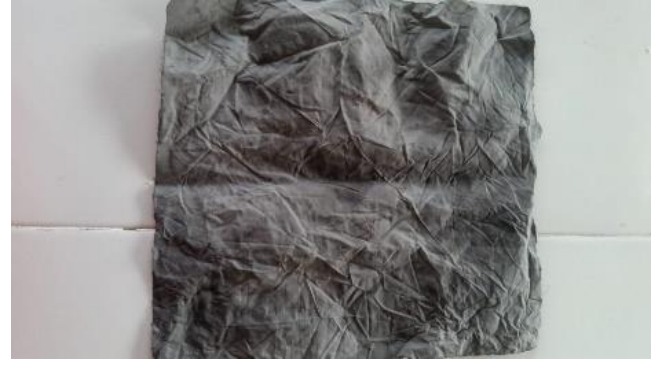

(a)

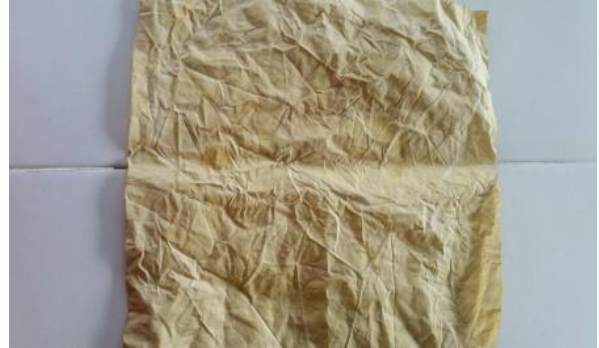

(b)

Figure 2. Photograph of dyed fabrics with: (a) ferrous sulphate; (b) alum

\section{Conclusion}

This study examined the dyeing of cotton fabric treated with chitosan using mango leaf extract as natural dye. In general, the results showed that the addition of chitosan to the cotton fabric before the dyeing process did not show a large effect on the color fastness of the dyed fabric, in terms of fastness to rubbing, washing and sun drying. However, the addition of chitosan in the pretreatment process of cotton fabric before dyeing gave higher $\mathrm{K} / \mathrm{S}$ values compared to the untreated fabric. Color analysis showed that the fabric processed using alum as mordant was brighter in color than that using ferrous sulphate.

\section{References}

Ali, N., El- Khatib, E., \& EL-Mohamedy, R. (2019). Improvement in Properties of Wool Fibers Pretreated with Chitosan and Nano- Chitosan and Dyed with Saffron Natural Dye. Egyptian Journal of Chemistry, 357-366.

Bulut, M., \& Akar, E. (2012). Ecological dyeing with some plant pulps on woolen yarn and cationized cotton fabric. Journal of Cleaner Production, Vol. 32, 1-9.

Chairat, M., Bremner, J., \& Chantrapromma , K. (2007). Dyeing of cotton and silk yarn with the extracted dye from the fruit hulls of mangosteen,Garcinia mangostana linn. Fibers and Polymers, Vol.8, 613-619.
Chilukoti, G., Venkatesh, B., \& Chandana, V. (2019). Optimisation of Dyeing and Mordanting Parameters onCotton Fabrics Treated With Allium Cepa as aNatural Dye Source. DYEING, 333339.

Davidson, R., \& Xue, Y. (1994). Improving the dyeability of wool by treatment with chitosan. Journal of the Society of Dyers and Colourists, Vol. 110, No. 1, 24-29.

Giri Dev, V., Venugopal, J., Sudha, S., Deepika, G., \& Ramakrishna, S. (2009). Dyeing and antimicrobial characteristics of chitosan treated wool fabrics with henna dye. Carbohydrate Polymers, Vol. 75, No. 4, 646-650.

Houshyar, S., \& Amirshahi, S. (2002). Treatment of Cotton with Chitosan and Its Effect on Dyeability with Reactive Dyes. Iranian Polymer Journal, Vol. 11, No. 5, 259-301.

Janhom, S., Watanesk, R., Watanesk, S., Griffiths, P., Arquero, O.-A., \& Naksata, W. (2006). Comparative study of lac dye adsorption on cotton fibre surface modified by synthetic and natural polymers. Dyes and Pigments, Vol. 71, No. 3, 188-193.

Kartikasari, E., \& Susiati, Y. (2016). Pengaruh Fiksator pada Ekstrak Daun Mangga dalam Pewarnaan Tekstil Batik Ditinjau dari Ketahanan Luntur Warna terhadap Keringat. Jurnal SCIENCETECH, Vol. 2, No. 1, 136143. 
Kavitha, T., Padmashwini, R., Swarna, A., Dev, V., Neelakandan, R., \& Kumar, M. (2007). Effect of chitosan treatment on the properties of turmeric dyed cotton yarn. Indian Journal of Fibre and Textile Research, Vol. 32, 53-56.

Kim, H., \& Park, S. (2007). Effects of introduced chemical groups on the dyeability of cotton fabrics with Phellodendron amurense Rupr. Dyes and Pigments, Vol. 75, No. 2, 351-355.

Ryu, S., \& Bae, H. (2018). Changes in the Adsorption Behavior of Coptidis Rhizoma Dyed Fabrics by Chitosan and Tannin Treatment. Fashion \& Textile Research Journal, Vol. 20, No. 2, 210218.

Sadeghi-Kiakhani, M., \& Safapour, S. (2019). Impact of Chitosanpoly(amidoamine) Dendreimer Hybrid Treatment on Dyeing and Color Fastness Properties of Wool Yarn with Madder Natural Dye. Progress in Color, Colorants and Coatings, Vol. 12, 241-250.

Safapour, S., Sadeghi-Kiakhani , M., \& Doustmohammadi, S. (2019). Chitosancyanuric chloride hybrid as an efficient novel bio-mordant for improvement of cochineal natural dye absorption on wool yarns. The Journal of The Textile Institute, Vol. 110, No. 1, 81-88.

Vakhitova, N., \& Safonov, V. (2003). Effect of Chitosan on the Efficiency of Dyeing Textiles with Active Dyes. Fibre Chemistry, Vol. 35, 27-28.

Yadav, M., Singh, N., Kaur, A., \& Sahu, O. (2019). Antibacterial activity assessment of woolen fabric treated with natural dyes and chitosan. Agriculture and Natural Resources, Vol. 53, No. 2, 188-196. 